
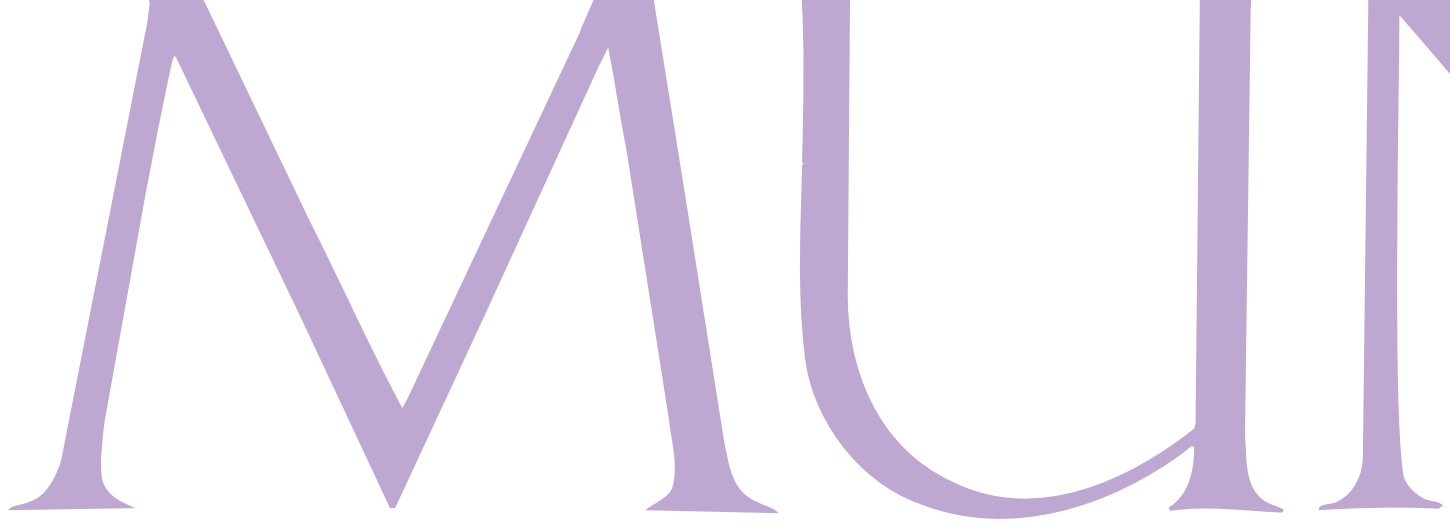

Quantas dessas estrelas podem existir no universo? Esta é, exatamente, uma das perguntas que Nascimento e sua equipe tentam responder, por meio de um recenseamento teórico com uma simulação computacional. 0 pesquisador, que tem apoio do Conselho Nacional de Desenvolvimento Científico e Tecnológico (CNPq), da Coordenação de Aperfeiçoamento de Pessoal de Nível Superior (Capes), da UFRN e da Fundação Lemman, comemora a inclusão de dois projetos seus na fase $\mathrm{K} 2$, no campo de M67: “O primeiro trata da observação de estrelas gigantes. Minha proposta é analisar a abundância de lítio desses objetos e entender melhor o processo de mistura que acontece no interior das estrelas. O segundo, e mais importante em curto prazo, trata da observação e busca por estrelas gêmeas". No último dia 2 de junho foi anunciada a descoberta da Mega Terra - a partir da análise de dados da Kepler. Um planeta 17 vezes mais maciço que a Terra, localizado na constelação de Draco. "Isso foi feito pelo meu vizinho de sala aqui em Harvard, o grande centro de pesquisa em astronomia da atualidade", conta Nascimento.

Victória Flório
Entrevista - Franck Seguy

\section{Pesquisador considera posição atual do Haiti na economia mundial como uma colônia dos países imperialistas}

Desde o terremoto de 2010, que matou 300 mil pessoas no Haiti e arrasou o território, o país está ocupado por tropas internacionais de militares que visam manter a ordem local. $\mathrm{O}$ episódio sísmico aumentou a diáspora haitiana pelo mundo e a fragilidade da população, que sofre com a falta de empregos, de infraestrutura e de autonomia. Para o sociólogo e pesquisador haitiano Franck Seguy, o Haiti ocupa a epiperiferia, pois além de estar na periferia dos Estados Unidos, passa a ser ocupado por países em desenvolvimento como o Brasil. Colônia francesa até 1804, quando obteve sua independência mediante pagamento de multa, o Haiti ainda não conquistou sua soberania e continua sendo explorado como colônia, sobretudo em função da fragilidade política, da mão de obra barata e especializada, afirma Seguy.

Em sua tese "A catástrofe de janeiro de 2010, a Internacional Comunitária e a recolonização do Haiti”, defendida na Universidade Estadual de Campinas (Unicamp), sob orienta- ção do sociólogo Ricardo Antunes, Seguy analisa a exploração sofrida pelo Haiti desde 1915, quando os norte-americanos se apossaram do território, embasando-se na doutrina Monroe que tem como lema: AAmérica para os americanos. "A América para os norte-americanos", corrige. Segundo o sociólogo, o interesse pelo Haiti ocorre pela posição estratégica ocupada, devido ao Canal do Panamá e à proximidade com grandes centros. Em 2004, com o golpe ao presidente Jean Bertrand Aristide, a Organização das Nações Unidas (ONU), ocupou o país e criou a Minustah, uma força militar para a estabilização do Haiti, conduzida há dez anos pelo Brasil. Para o pesquisador, a missão não é evitar conflitos no país, mas movimentos sociais contrários à política das zonas francas e às condições trabalhistas precárias.

Nesta entrevista, Seguy aborda questôes polêmicas sobre a situação atual do Haiti. "O Haiti é a nova colônia dos Estados Unidos que, entre outros interesses, fazem uso da mão de obra barata para fomentar indústrias norte-americanas", aponta referindo-se às relações desiguais entre os países que devem se intensificar com a criação de 42 novas zonas francas no Haiti. O sociólogo defende a retirada imediata das tropas militares.

Em sua tese, você cita um estudo do economista norte-americano Paul 


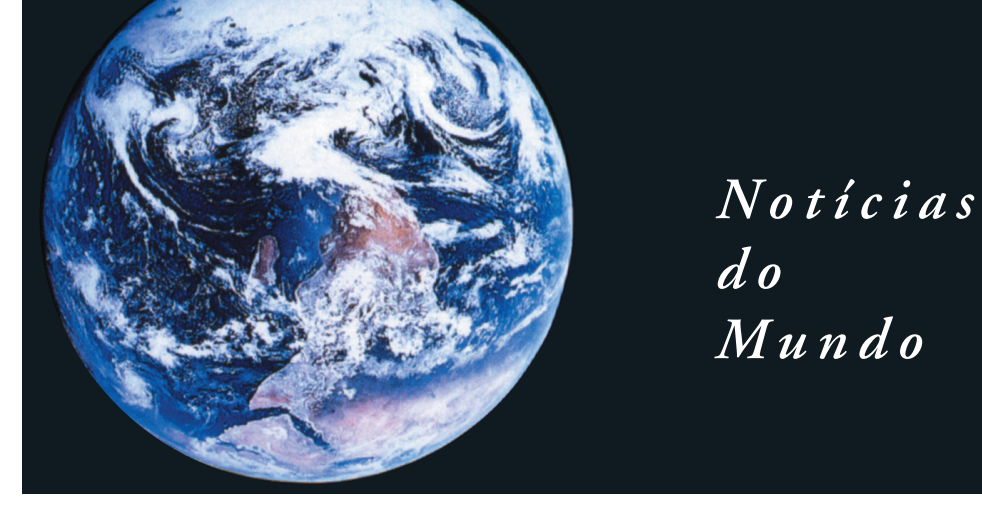

Collier sobre controle da mão de obra haitiana, um ano antes do terremoto. Você acredita que o sismo criou as condições para que esse projeto fosse posto em prática?

Desde 1915, o Haiti não deixou de ser um tipo de propriedade privada dos sucessivos governos norte-americanos; apenas as formas de cada governo lidar com o Haiti é que mudam de acordo com o contexto. Atualmente, o conceito fundamental para entender essa dominação é a lei PARDN (Plano de Ação para Reerguer e Desenvolver o Haiti), ou lei Hope, como é conhecida no Haiti. Esta lei nasceu em 2006, a partir do relatório do economista norte-americano, Paul Collier, enviado ao país pelo secretário geral da ONU. O economista apresentou o relatório, em 2009, que foi posto em prática após a destruição que o país sofreu em 2010, devido ao terremoto. $\mathrm{O}$ plano emergencial para reerguer a economia haitiana era, na verdade, uma medida premeditada que encontrou, no terremoto, o cenário perfeito para se realizar.

Qual o teor da lei Hope e como ela impacta o Haiti?

No relatório, o economista diz que o Haiti é um país que possui estabilidade social e que é estratégico, por ser vizinho de grandes mercados. Possui, ainda, mão de obra mais barata que a chinesa, e é um país pou-

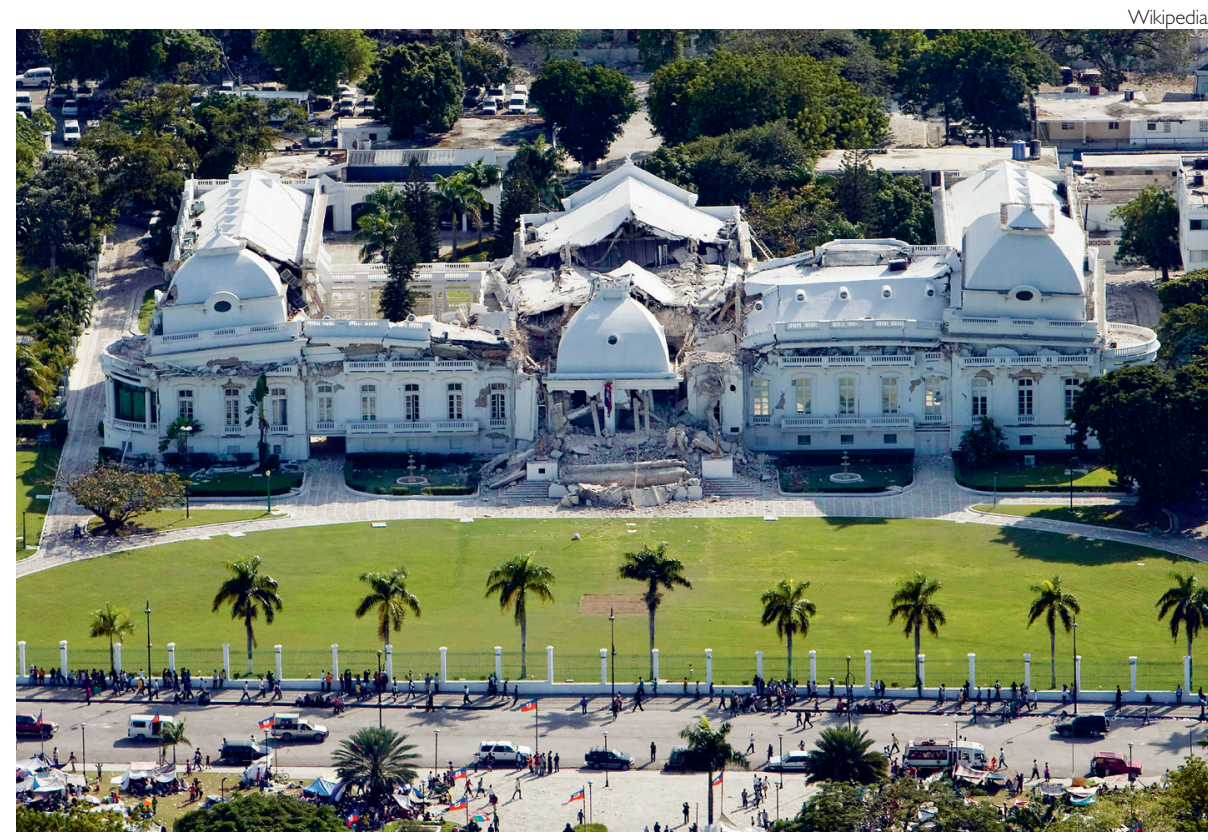

Palácio nacional haitiano na capital Porto Príncipe, abalado pelo terremoto que causou cerca de $\mathbf{3 0 0}$ mil mortes, foi demolido em 2012

co regulamentado, sem muitas leis trabalhistas, sindicatos ou proteção ao trabalhador. Além disso, oferece trabalhadores qualificados, pois o país tem tradição na produção têxtil oriunda das décadas de 1960, 1970 e 1980, dispensando, assim, treinamento oneroso para as empresas. $\mathrm{O}$ economista acrescenta que, do ponto de vista da indústria do vestuário, o Haiti é o país mais seguro para investir. Empresas que produzem artigos como calçados e vestuários no Haiti têm a liberdade de entrar no mercado norte-americano sem pagar impostos. Já para produtos, que estão nos EUA, voltarem para o Haiti e serem comercializados, há duas condições: a porcentagem da produção que pode voltar para o país de origem é de 25 a 30\%. Quando o produto volta para o Haiti, torna-se mercadoria importada, ou seja, deve-se pagar taxas de importação para adquirir o produto em solo haitiano. Esse plano é fundamental para entender todo o processo em andamento, que não dispensa a construção de zonas francas em pontos estratégicos do país.

Como se dá o processo de construção de zonas francas?

O Haiti é a nova colônia dos Estados Unidos, com sua produção destinada somente àquele mercado e com 
